\title{
Medical student career choice's determinants in Asia: a systematic review
}

\author{
Rosyila $^{1}$, Rizma Adlia Syakurah ${ }^{2}$ \\ ${ }^{1}$ Medical Faculty, Sriwijaya University, Indonesia \\ ${ }^{2}$ Public Health Faculty, Sriwijaya University, Indonesia
}

\begin{tabular}{l}
\hline Article Info \\
\hline Article history: \\
Received Jan 3, 2020 \\
Revised Feb 13, 2020 \\
Accepted Feb 28, 2020 \\
\hline
\end{tabular}

Keywords:

Career choice

Medical career choice

Medical student

Undergraduate

\begin{abstract}
Asian countries have distinctive cultural patterns and norms that influence one's decision making process throughout their life, including career choice. This review was intended to explore factors influencing medical students' career choice in Asia. This review was compiled based on guidelines from PRISMA (Preferred Reporting Items for systematic reviews and Meta-Analysis). Data was searched and collected from studies published from electronic databases such as Pubmed, Europe PMC, Cochrane Databases, Science Direct, BMC Medical Education, ACM, Wiley Online Library and Mendeley with the keyword "medical student" and "career choice's determinants" or "medical students" and "career determinant" and "Asia". Six studies were found to match the inclusion criteria for this review. Five cross-sectional and one prospective cohort studies involving a total of 1.862 participants that were published between January 1986 and December 2017 were included. Among the included studies, the main findings were grouped into five main determinants: personal interest, family influence, prestigious profession, secure profession, and financial reward. Personal interest was the most influential factor that contributed to Asian medical student career choice's determinants. It also highlights clinical specialist as unanimous career choice.
\end{abstract}

This is an open access article under the CC BY-SA license.

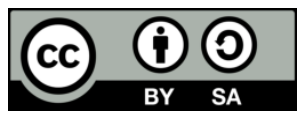

\section{Corresponding Author:}

Rizma Adlia Syakurah,

Public Health Faculty,

Sriwijaya University,

Jl. Raya Palembang-Prabumulih KM. 32 Indralaya, Ogan Ilir, Sumatera Selatan, 30662, Indonesia.

Email: rizma@fkm.unsri.ac.id

\section{INTRODUCTION}

Career choice is one of major decision-making process that needs to be done by medical students. This sets pressure on medical students to choose a possibly irreversible career path that will they pursue their whole life. Career choice is not only important for medical students, but also for the wider community who will be provided services with a variety of medical specialties [1]. Settling on a career choice decision and choosing to practice or not is a confused method orientated by social impacts, however considerably more by the general restorative school culture and encounters [2]. Career choices of a doctor can be divided into two career fields, namely clinical (primary care physician or specialist) and non-clinical (basic medicine, community medicine, health administration, researchers, lecturers, industry, pharmacy and others) [3]. The writing on profession decision has recognized impacts that can be extensively sorted as understudies socioeconomics, medicinal school attributes, understudies view of claim to fame attributes and understudy held. Differing factors impact restorative understudies' decision of possible vocation; 
profession inclination at the hour of admission to the therapeutic course is thought to assume a significant job [4].

Many factors impact the career choices made by medical students. These range from the attributes of individuals to the apparent advantages of specific specialties to factors related with medical school educational curricula, such as, experience of the chosen specialty [5]. Factors that influence career choice in medical students are varied greatly, and in Asia, those factors included some collectivist-type determinants such as the influence of family or parents, and prestige of the profession. Medical education proceeds all through a specialist's vocation and those in the calling travel down a way of constant learning [6]. Certain pattern of parental approval and collective decision making are common occurrences especially in environments with collectivism cultures such as in Asia; where the views of family, friends, or certain people are considered very influential and important to make life-changing decision, including career choice decisions [7]. A few elements impact profession decision of medicinal students. Factors, for example, personal preference and controllable way of life give off an impression of being a higher priority than conventional inspirations for example, compensation, notoriety and length of preparing. A few investigations tended to the lifestyle priorities of the current ages of medical students who do not want to sacrifice their family and social life by pursuing some specialities like surgery [8].

In general, the community also considers the medical profession as a prestigious career [9]. Most of medical students choose medical careers, especially clinical specialties because being a specialist is identical for having a lot of money or highly-paid and considered as prestigious profession [10]. Factors, for example, way of life and salary are significant for male and female graduating students and have been strongly connected with trends in specialty choices [11]. Medical students who choose a medical career based on their own desires are influenced by personal lifestyle, motivation, and some stated that the choice is also influenced by their future plans on having family and wanting to spend more time with family [7]. Numerous students today have progressively various interests; along these lines, when they apply for postgraduate preparing, they may favor claims to fame in which an increasingly adaptable way to deal with preparing is an alternative to permit them to incorporate other expert and family interests [12]. The choice of career paths chosen by medical students contributes to the health development system in their respective countries and there is a major necessity to identify the needs of physicians for the effective healthcare system [13]. Therefore, this review was intended to explore the determinants of medical students' career choice in Asia.

\section{RESEARCH METHOD}

This review was compiled based on guidelines from PRISMA (Preferred Reporting Items for systematic reviews and Meta-Analysis). This study identifies determinants of career choice for medical students in Asia. There was no publication limit in searching and collecting data, and the data were collected from studies published from electronic databases such as Pubmed, Europe PMC, Cochrane Databases, Science Direct, BMC Medical Education, ACM, Wiley Online Library and Mendeley with the keyword "medical student" and "career choice's determinants" or "medical students" and "career determinant" and "Asia". This study is limited to studies with texts in English. Further strategies to maximize the scope of research, namely by various combinations of keywords such as "medical career determinant" or "influencing factor of medical careers" Figure 1.

Search of the literature was performed in September 2019. Duplicate articles in both databases were eliminated from one set of the search results. Titles and abstracts were screened by authors divided into two groups. After the abstracts were screened, the full text of the remaining articles was screened together in order to conclude which articles would be included in the review. The articles chosen from the screening process were analysed by the authors for data extraction, and the findings were discussed with the group. The data extraction table is then used to extract the characteristics of each study and the main findings, which include the author, year of publication, study design, sample size, sample age range, parent's occupation, monthly allowances, career plans, and career choice determinants.

\section{RESULTS AND DISCUSSIONS}

The literature search yielded in 274 studies, of which 259 were excluded after screening for duplication and titles and abstracts screening, leaving 15 potentially relevant studies to be retrieved for full-text assessment. Among the 15 remaining studies 9 were excluded because they were either in non-English language, irrelevant topics, or data insufficiency. We include 6 studies that were found to match the inclusion criteria for this systematic review Figure 1. 


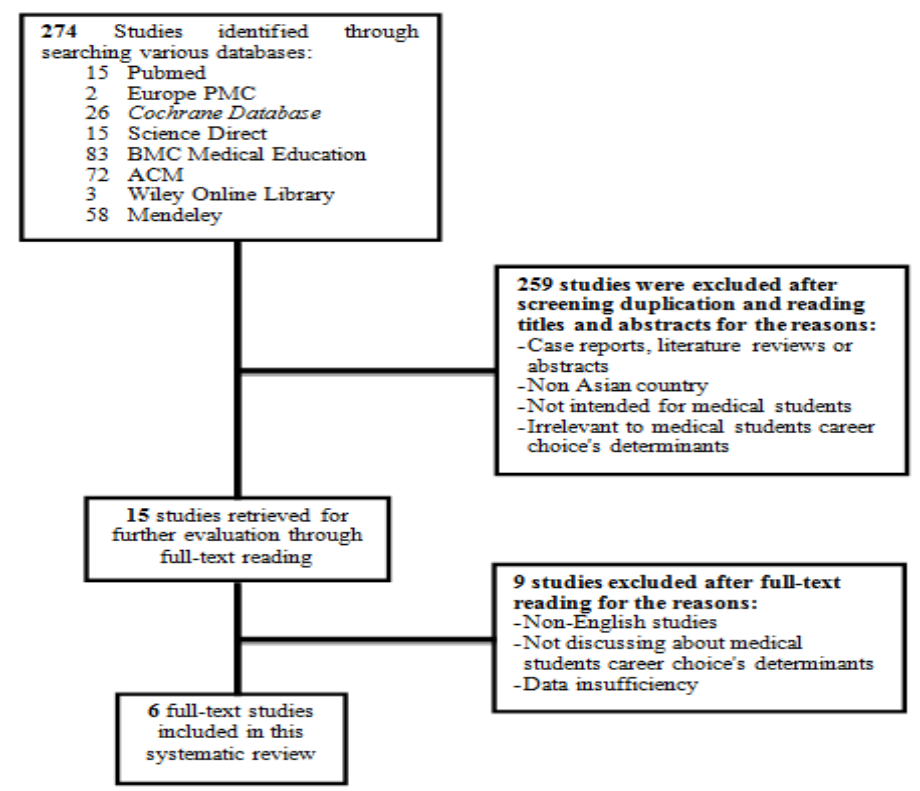

Figure 1. Flow diagram of the screening and selection process of the articles

\subsection{Study characteristics}

Five cross-sectional and one prospective cohort studies involving a total of 1.862 participants that were published between January 1986 and December 2017 were included in this research Table 1. These studies were conducted in India, Pakistan, Sri Lanka, Indonesia, Malaysia, and Bangladesh.

Table 1. Included studies characteristics [7-12]

\begin{tabular}{|c|c|c|c|c|c|c|c|c|c|}
\hline No & Study & Country & Design & $\begin{array}{l}\text { Sample } \\
\text { size (n) }\end{array}$ & $\begin{array}{c}\text { Age } \\
\text { range } \\
\text { (years) }\end{array}$ & $\operatorname{Sex}(\%)$ & $\begin{array}{l}\text { Relationship } \\
\text { Status }(\%)\end{array}$ & $\begin{array}{c}\text { Parent's Job } \\
(\%)\end{array}$ & $\begin{array}{c}\text { Duration } \\
\text { for study } \\
\text { design } \\
\end{array}$ \\
\hline 1. & $\begin{array}{c}\text { Diwan et al., } \\
2013\end{array}$ & India & $\begin{array}{c}\text { Cross } \\
\text { sectional }\end{array}$ & 792 & $18-31$ & Male $(59,5)$ & N/A & $\begin{array}{c}\text { Physician } \\
(21,7)\end{array}$ & 4 months \\
\hline 2. & $\begin{array}{l}\text { Huda et al., } \\
2006\end{array}$ & Pakistan & Prospective & 232 & N/A & $\begin{array}{c}\text { Male (31) } \\
\text { Female (69) }\end{array}$ & N/A & N/A & 5 years \\
\hline 3. & $\begin{array}{l}\text { Karalliedde } e t \\
\text { al., } 1986\end{array}$ & Sri Lanka & $\begin{array}{c}\text { Cross } \\
\text { sectional }\end{array}$ & 196 & $23-27$ & Male (56) & Married (1) & N/A & 1 month \\
\hline 4. & $\begin{array}{c}\text { Syakurah et al., } \\
2017\end{array}$ & Indonesia & $\begin{array}{c}\text { Cross } \\
\text { sectional }\end{array}$ & 269 & $16-17$ & N/A & N/A & N/A & 2 weeks \\
\hline 5. & $\begin{array}{l}\text { Zulkifli et al., } \\
1997\end{array}$ & Malaysia & $\begin{array}{c}\text { Cross } \\
\text { sectional }\end{array}$ & 241 & N/A & $\begin{array}{c}\text { Male }(44,4) \\
\text { Female } \\
(55,6)\end{array}$ & $\begin{array}{c}\text { Married } \\
\text { Male }(6,2) \\
\text { Female }(12,9)\end{array}$ & N/A & 2 years \\
\hline 6. & $\begin{array}{c}\text { Ahmed et al., } \\
2011\end{array}$ & Bangladesh & $\begin{array}{c}\text { Cross } \\
\text { sectional }\end{array}$ & 132 & N/A & $\begin{array}{c}\text { Male (35) } \\
\text { Female (65) }\end{array}$ & N/A & N/A & 1 month \\
\hline
\end{tabular}

\subsection{Medical students career choices' determinants}

Main findings were grouped into five main determinants: personal Interest, family influence, prestigious profession, secure profession, and financial reward Table 2. Among all determinants, based on included studies, it was shown that the most influential determinant for career choice in Asian medical students was personal interest.

\subsection{Summary of evidence}

From the evidence of the review, it is shown that Asian medical students' career choices have partly similar determinants with western medical students, such as personal interest, financial reward, secure profession and prestigious profession. Family influence came as the unique determinant that paints the uniqueness of the community, the collectivist community such Asian countries. However, their personal interest, the most influential determinant, also stated to be influenced by their family-oriented values, such as future plan about setting up family, and considering on spending more time with them. Others determinants also slightly influence by family and community point of views and expectations. Details of the determinants are explained below. 
Table 2. Medical students career choices' determinants of included studies [7-12]

\begin{tabular}{|c|c|c|c|c|c|c|c|c|}
\hline No & Study & Design & Sample & $\begin{array}{c}\text { Personal } \\
\text { Interest } \\
(\%)\end{array}$ & $\begin{array}{c}\text { Family } \\
\text { Influence } \\
(\%)\end{array}$ & $\begin{array}{c}\text { Prestigious } \\
\text { Profession } \\
(\%)\end{array}$ & $\begin{array}{c}\text { Secure } \\
\text { Profession } \\
(\%)\end{array}$ & $\begin{array}{c}\text { Financial } \\
\text { Reward } \\
(\%)\end{array}$ \\
\hline 1. & Diwan et al., 2013 & Cross sectional & 792 & 23 & 22,7 & 11,5 & 14,4 & 5,9 \\
\hline 2. & Huda et al., 2006 & Prospective & 232 & 87,5 & 47,5 & 53,9 & N/A & 53 \\
\hline 3. & Karalliedde et al., 1986 & Cross sectional & 196 & N/A & N/A & 10 & N/A & 12 \\
\hline 4. & Syakurah et al., 2017 & Cross sectional & 269 & 38,4 & 6,8 & 20,9 & 1,5 & 8,6 \\
\hline 5. & Zulkifli et al., 1997 & Cross sectional & 241 & N/A & N/A & 4,75 & N/A & 5,05 \\
\hline 6. & Ahmed et al., 2011 & Cross sectional & 132 & 81 & N/A & N/A & N/A & 35 \\
\hline
\end{tabular}

\subsection{Personal interest}

It is presented from the included study that personal interest was the most influencing factor that contributed to determine Asian medical students' career choices [14-17]. It is further explained that medical students who choose a medical career based on their own desires are influenced by personal lifestyle, intrinsic motivation, and one study specifically stated that the choice is also influenced by their future plan, such as having family or their personal value such as wanting to spend more time with family [7, 16] that exhibited a distinctive collectivism and family-oriented behaviour. Similar to studies elsewhere, intrinsic factors such as personal interest and professional independence are highly rated compared to extrinsic factors like parental preference, financial rewards, fixed working hours, etc. [16, 18]. Medical students were unimportantly more affected by "Playing a role in community health promotion". Also, "personal interest" was a more grounded persuasive factor among medical students [19].

\subsection{Family influence}

Public or community point of view on careers in the medical field in Asian countries remained generally the same, which is to assume that the next step of becoming a doctor is to become medical specialist. Therefore, parents or families are more likely to recommend them to be one, hence parental or family influence became one of the determinants of Asian medical students' career choices [14, 15, 17]. The views of family, friends, or certain people are very influential and considered important to career choice decisions [10]. This determinant doesn't particularly influence medical career fields nor on college level only, but it's actually a general theme throughout the life of decision-making process of someone living in Asian countries, especially those that still withholding inherited norms and cultures [20, 21].

\subsection{Prestigious profession and financial reward}

From all included studies above reported most of medical students choose clinical specialties as their preferred medical career [14,22]. Both medical students and the community in Asia have the same understanding on this matter, that being a clinical specialist is identical for a prestigious profession that come with financial reward consequently $[9,13]$. Clinical specialties were generally considered highly-rated and highly-compensated financially compared to other medical careers. As the studies found that financial reward as one of the determinant of Asian medical students' career choices, it was further stated that specifically more males indicated financial reward and social prestige as important considerations in the choice of career [15, 17, 23].

\subsection{Secure profession}

Secure profession as determinant for Asian medical students' career choice hold quite a different place with prestigious and financial reward determinants. Security is not about the pay check or the prestige that come with the degree, but more of the higher prospects and career stability [14, 16]. An ongoing report of medical students motivation uncovered need accentuation being placed upon 'person orientated' factors, with financial status and security factors considered of lesser significance [24]. Opportunities for finding a job after finishing their clinical specialty study are abound for doctors, especially in rural areas that have great difficulty recruiting and retaining physicians. Although both determinants, prestige and security, are two different aspects, they are surprisingly hold the same collectivist principle, whereas both determinants are commended by not only medical students but also general community, and also related to family and parental issues, which again provide us with a typical collectivism-style behavior [21]. Factors that were considered moderately less persuasive were "future job opportunities," "geographical locations," and "influence from a mentor" [25].

\subsection{Limitations}

Researches for medical career choices in Asia are growing, but amount are still limited, the topic are also narrowed down to specific clinical specialty career choices, or clinical specialty career choices only. Nonetheless, publications in this review were limited to English-written studies; hence important 
and culturally specific works published in other languages in Asian countries might have not been well represented.

\section{CONCLUSION}

Evidence shown that medical students' career choices in Asian are inevitably influenced by the collectivism culture in Asia. Important determinants contributed to their career choices are personal interest, financial reward, prestigious profession, family influence and secure profession in which clinical specialty was unanimously chosen as their preferred career choice. Understanding the unique characteristics of medical students' pattern of career choice is major in shaping the curricula and regulation to adhere the need of government and society to improve quality of healthcare in Asian countries.

\section{REFERENCES}

[1] Querido S, et al., "Factors affecting senior medical students' career choice," International Journal of Medical Education, vol. 9, pp. 332-339, 2018.

[2] Avgerinos ED, et al., "Greek medical students ' career choices indicate strong tendency towards specialization and training abroad," Health Policy, vol. 79, pp. 101-106, 2006;

[3] Syakurah RA, et al., "Determination of career choices for medical faculty students in Indonesia (In Bahasa: Determinan pilihan karir mahasiswa fakultas Kedokteran sebagai spesialis di Indonesia)," Jurnal Pendidikan Kedokteran Indonesia, vol. 3, no. 2, pp. 132-136, 2014

[4] Kumar R., et al., "Career choices of undergraduate medical students," The National Medical Journal of India. vol. 24, no. 3, pp. 166-169, November, 2010.

[5] Cleland J, et al., "Making choices Associations between medical school and career preferences in Year 1 medical students in Scotland," Medical Education, vol. 46, pp. 473-484, 2012.

[6] Al-nuaimi Y, et al.," Modernising medical careers and factors influencing career choices of medical students," British Journal of Hospital Medicine, vol. 69, no. 3, pp. 163-166, 2008;

[7] Syakurah RA, et al., "Medical Student Career Choice's Determinants: A Qualitative Study," Global Medical and Health Communication, vol. 5, no. 3, pp. 236-40, 2017.

[8] Abouzaid LZ, et al., "Career choice and its influencing factors : Perception of senior medical students," Journal of Contemporary Medical Education, vol. 2, no. 3, pp. 168-173, 2015.

[9] Kim K, et al., "What is different about medical students interested in non-clinical careers ?," BMC Medical Education, vol. 13, no. 81, 2013.

[10] Girasek E, et al., "The medical career choice motivations-Results from a Hungarian study," Central European Journal of Medicine, vol. 6, no. 4, pp. 502-509, 2011.

[11] Marshall DC, et al., "Medical Student Experience in Surgery Influences Their Career Choices: A Systematic Review of the Literature, Journal of surgical education, vol 72, no. 3, pp. 438-5, 2014.

[12] Sanfey HA, et al., "Influences on Medical Student Career Choice," Arch Surg., vol. 141, pp. 1086-1094, 2006.

[13] Ackerly DC,et al., "Health Systems Improvement," Academic Medicine, vol. 88, no. 1, pp. 56-60, 2013.

[14] Diwan V, et al., "Indian Medical students in public and private sector medical schools: are motivations and career aspirations different?-studies from Madhya Pradesh, India," BMC Medical Education, vol. 13, pp. 127, 2013.

[15] Huda N and Yousuf S, "Career Preference of Final Year Medical Students of Ziauddin Medical University," Education for Health Taylor \& Franci, vol. 19, no. 3, pp. 345-53, 2006.

[16] Syakurah RA, et al., "Career choices, determinants, and need for medical career introduction among medicalstudents," International Journal of Research in Medical Sciences, vol. 5, no. 5, pp. 1998-2002, 2017.

[17] Ahmed SMM, et al., "Career choices among medical students in Bangladesh," Advances in Medical Education and Practice, no. 2, pp. 51-8, 2011.

[18] Lawrence J, et al., "Critical factors in career decision making for women medical graduates," Medical Education. vol. 37, no. 4, pp. 319-27, 2003.

[19] Dastjerdi MV, et al., "Study Motives and Career Choices of Iranian Medical and Dental Students," Acta Medica Iranica, vol. 50, no. 6, 2012.

[20] Sawitri DR, Creed PA, Zimmer-Gembeck MJ., "Longitudinal relations of parental influences and adolescent career aspirations and actions in a collectivist society," Journal of Research on Adolescence, vol. 25, no. 3, pp. 551-63, 2015.

[21] Hofstede G, Hofstede GJ, Minkov M., "Cultures and organizations: Software of the mind." Mcgraw hill, New York, Apr 2005

[22] Zulkifli A, et al.,"Career preferences of male and female medical students in Malaysia," Med J Malaysia, vol. 52, no. 1, pp. 76-81, Apr. 1997.

[23] Karalliedde LD, Senanayake N, and Aluwihare PR., "Career preferences of the 1984 medical graduates of SriLanka," Medical Educution, vol. 20, pp. 64-68, 1986.

[24] Crossley ML, et al. "A comparative investigation of dental and medical student's motivation towards career choice," Acta Medica Iranica, vol. 193, no. 8, pp. 471-473, 2002.

[25] Hin Hin Ko, et al., "Factors influencing career choices made by medical students, residents, and practising physician," Bc medical journal, vol. 49, no. 9, pp. 482-489, 2007. 